\title{
Editorial Comment: An Effective Evidence-Based Cleaning Method for the Safe Reuse of Intermittent Urinary Catheters: In Vitro Testing
}

Wilks SA ${ }^{1,2}$, Morris NS ${ }^{3}$, Thompson $\mathrm{R}^{3}$, Prieto JA ${ }^{1}$, Macaulay M ${ }^{1}$, Moore KN ${ }^{4}$, et al.

' School of Health Sciences, Faculty of Environmental and Life Sciences, University of Southampton, Highfield Southampton, UK; ${ }^{2}$ School of Biological Sciences, Faculty of Environmental and Life Sciences, University of Southampton, Highfield Southampton, UK; ${ }^{3}$ Bristol Urological Institute, North Bristol NHS Trust, Southmead Hospital, Bristol, UK; ${ }^{4}$ Faculty of Nursing, University of Alberta, Edmonton, Canada

Neurourol Urodyn. 2020 Mar;39(3):907-915

DOI: 10.1002/nau.24296 | ACCESS: 10.1002/nau.24296

Marcio Augusto Averbeck ${ }^{1}$, Blayne Welk ${ }^{2}$

${ }^{1}$ Chefe de Neuro-Urologia, Unidade de Videourodinâmica, Hospital Moinhos de Vento. Porto Alegre, RS, Brasil; ${ }^{2}$ Department of Surgery and Epidemiology \& Biostatistics, Western University, London ON Canada

\section{COMMENT}

The article published by Wilks et al. (1) is a nice contemporary examination of the in vitro performance of different types of cleaning methods for uncoated urinary catheters. Their methods advance the work of previous studies as they used two types of artificial urine media, assessed for viable but nonculturable bacteria (bacteria which are just "stunned" but could still potentially cause an infection), and assessed surface structural damage. While many of the traditional methods did well and were able to eliminate culturable bacteria, these methods often resulted in the development of "stunned" bacteria. The 3 heat-based methods (steam, boiling, microwave) all changed the mechanical properties of the catheters. Ultrasonic cleaning and vinegar showed evidence of viable but nonculturable bacteria populations, indicating the methods were bacteriostatic. Detergent and water wash followed by immersion in a commercially available $0.6 \%$ sodium hypochlorite solution and 16.5\% sodium chloride (diluted Milton) gave consistent bactericidal results and no visible catheter damage.

While there is good agreement that intermittent catheterization (IC) represents the ideal method of managing a bladder that fails to empty, the optimal way to do IC is still a subject of controversy. The options around single use/multiple use, and the relative benefit of different types of catheter coatings are still debated. A recent, well done randomised trial in patients with spina bifida did not show a benefit in terms of UTI 
reduction over 8 weeks when intermittent catheters were reused compared to when catheters were only used once (35.2\% vs $36.8 \%, p=0.877$ ) (2). It is still common for patients to reuse uncoated catheters for IC (for example in Brazil, Canada and many developing countries), and thus the question about caring for reused catheters is still relevant.

Hydrophilic catheters have been introduced to the urological practice as an alternative to reduce the risk of recurrent UTI and urethral trauma (3). However, associated costs are higher in comparison to clean intermittent catheterization (CIC), which has been the standard since it was proposed by Lapides decades ago (4). One of the most frustrating things for patients is the lack of information from physicians about how to practically reuse catheters. In the neurogenic population, complex methods add an additional burden to a person's daily routine. Over

\section{CONFLICT OF INTEREST}

None declared.

\section{REFERENCES}

1. Wilks SA, Morris NS, Thompson R, Prieto JA, Macaulay M, Moore KN, et al. An effective evidence-based cleaning method for the safe reuse of intermittent urinary catheters: In vitro testing. Neurourol Urodyn. 2020;39:907-15.

2. Madero-Morales PA, Robles-Torres JI, Vizcarra-Mata G, GuillénLozoya AH, Mendoza-Olazarán S, Garza-González E, et al. Randomized Clinical Trial Using Sterile Single Use and Reused Polyvinylchloride Catheters for Intermittent Catheterization with a Clean Technique in Spina Bifida Cases: Short-Term Urinary Tract Infection Outcomes. J Urol. 2019;202:153-8.

3. Li L, Ye W, Ruan H, Yang B, Zhang S, Li L. Impact of hydrophilic catheters on urinary tract infections in people with spinal cord injury: systematic review and meta-analysis of randomized controlled trials. Arch Phys Med Rehabil. 2013;94:782-7.

4. Lapides J, Diokno AC, Silber SJ, Lowe BS. Clean, intermittent self-catheterization in the treatment of urinary tract disease. $\mathrm{J}$ Urol. 1972;107:458-61.

5. Biering-Sørensen F. Urinary tract infection in individuals with spinal cord lesion. Curr Opin Urol. 2002;12:45-9.

6. Truzzi JC, Teich V, Pepe C. Can hydrophilic coated catheters be beneficial for the public healthcare system in Brazil? - A costeffectiveness analysis in patients with spinal cord injuries. Int Braz J Urol. 2018;44:121-31. the years, patients have described varied routines, ranging from using one catheter a week and rinsing it in tap water, to more complex cleaning processes involving vinegar, dilute bleach, freezing and microwaving.

Despite the promising laboratory results published by Wilks et al, clinical studies are still needed to check whether diluted Milton strategy is effective and safe for patients. Bacterial biofilm still represents an important barrier for patients who reuse catheters (5). A general limitation of most uncoated PVC catheters is that they contain softeners such as phthalates that may put the users at risk of certain diseases (6). In the general population, exposure to some phthalate diesters is a cause of increasing concern because of their potential adverse effects on the reproductive and endocrine systems (7).

7. Cutanda F, Koch HM, Esteban M, Sánchez J, Angerer J, Castaño A. Urinary levels of eight phthalate metabolites and bisphenol A in mother-child pairs from two Spanish locations. Int J Hyg Environ Health. 2015;218:47-57.

Marcio Averbeck, MD, PhD

Unidade de Videourodinâmica, Hospital Moinhos de Vento. Porto Alegre, RS, Brasil E-mail:marcio@averbeck.com.br

\section{ARTICLE INFO}

Marcio Averbeck https://orcid.org/0000-0002-8127-7153

Int Braz J Urol. 2020; 46: 843-4 